\title{
Social network analysis in sport research: an emerging paradigm
}

\author{
Hagen Wäsche ${ }^{a}$, Geoff Dickson ${ }^{b}$, Alexander Woll ${ }^{a}$ and Ulrik Brandes ${ }^{c}$ \\ aDepartment of Sports and Sports Science, Karlsruhe Institute of Technology, Karlsruhe, Germany; \\ ${ }^{\mathrm{b}}$ School of Sport and Recreation, Auckland University of Technology, Auckland, New Zealand; \\ 'Department of Computer and Information Science, University of Konstanz, Konstanz, Germany
}

\begin{abstract}
While network analysis is a major methodological approach in many disciplines of the social and natural sciences, it has only recently come into the focus of sport researchers. This article assesses the utility of network analysis to analyze sport phenomena. We begin with an overview of social network analysis (SNA) and related concepts. To explore research topics and approaches, we conduct a systematic review of empirical literature of SNA and its application to sport. Based on this review, we provide a sixdimensional conceptual typology of SNA applications in sport competition networks, interaction networks, inter-organizational networks, intra-organizational networks, affiliation networks and social environments. Potential future directions for this promising approach in sport research are discussed.
\end{abstract}

Social network analysis (SNA) is a combination of theory and methods in which relations take precedence over, or at least are on par with, the characteristics of actors engaged in them (Wasserman \& Faust, 1994; Kadushin, 2012; Hennig, Brandes, Pfeffer, \& Mergel, 2012; Borgatti, Everett \& Johnson, 2013). Based on formal, mathematical theory, SNA is an interdisciplinary approach that emerged in the 1930s from sociology and psychology. With a strong focus on the systematic analysis of empirical data, SNA's evolution was more recently accelerated by methodological and computational developments (Freeman, 2004). Today, SNA, as an applied form of network science (Brandes, Robins, McCranie, \& Wasserman, 2013), is a widely established approach with relevance to organizational theory, management, economics, public health, political science, computer science, and physics, amongst others (Borgatti, Mehra, Brass, \& Labianca, 2009; Provan, Fish, \& Sydow, 2007; Zaheer, Gözübüyük, \& Milanov, 2010). The value of SNA lies in a perspective that is fundamentally different from more common approaches that focus on population samples of actors. Whereas traditional empirical research in the social sciences utilizes autonomous and independent actors as the fundamental unit of observation, the distinctive feature of network analysis is that it 
includes the relationships between social actors or other interdependent social entities. Emirbayer (1997) thus describes it as a relational perspective in contrast to the substantialist perspective. ${ }^{1}$

Since sport research is a relatively young scientific discipline, the adoption of research methods and theories from other disciplines has proven useful. Given the plethora of connected actors in sport, a cross-disciplinary and theoretically informed approach based on a relational perspective such as network analysis holds great promise. The aim of this paper is to assess the utility of SNA for the analysis of social phenomena in sport. Following a general overview of SNA and related concepts in sport research, a systematic review of empirical literature identifies what is researched and how this is done. This permits organization and categorization of the body of literature. The main purpose of the review is, however, to develop a conceptual typology of network analysis in the context of sport that helps to organize this new field of research. In a final synthesis we draw our conclusions from what we have analyzed and discuss future directions.

\section{Social network analysis}

The term 'social network' is a catchphrase, not only in the context of social media, but also in academic writing as a metaphor for anything from alliances, coalitions, clusters and groups. A salient example for the metaphoric use of the term network is its use in studies on social capital, when it is considered as originating from networks that are referred to without any empirical investigation on their existence, formation, or availability (Diaz-Bone, 2006).

In empirical SNA, the characteristics of a network must be made explicit. First, the focus lies on the linkages or relations between the actors. This perspective implies a fundamental shift from traditional approaches in social sciences focusing on attributive categories of individuals to relational processes or transactions between individuals. Second, the set of actors to be considered has to be delineated. Boundary specification of networks can be problematic. If anything, the popular studies of Milgram (1967) and later Watts (1999) show that even the seemingly most remote individuals can be connected via few social ties, an observation referred to as the 'small world phenomenon' (Schnettler, 2009). The third aspect is the emergent character of networks. Put simply, a system as a whole can develop characteristics that are markedly different from those of its parts. Therefore, exclusively element-level analysis is insufficient for understanding a system.

\section{Basic concepts and data}

In network terminology actors are called nodes and can be connected through ties such as communication or friendship. Brass, Galaskiewicz, Greve, and Tsai $(2004,795)$ define a network 'as a set of nodes and the set of ties representing some relationship, or lack of relationship, between the nodes'. The decisive characteristic of SNA is that the main unit of observation is a dyad, which consists of two nodes and their relations. While individual actors (i.e. single nodes) are the most common unit of analysis, the first non-trivial level of analysis is a triad - a collection of three nodes. On an 
intermediate level, subgroups within one network are of interest, and the highest level of analysis is the level of the network itself.

To conduct an SNA, researchers identify a network by deciding which nodes and ties (i.e. network data) to analyze. Social actors such as persons, groups, organizations, teams or social artifacts (e.g. concepts) represent nodes suitable for analysis. Ties can be directed or undirected and weighted or unweighted. Whereas friendship is usually reciprocal and as such undirected, the flow of information may take only one direction. In some analyses tie strength is relevant. The strength of the ties can be quantified and weighted accordingly. In SNA four types of ties are commonly analyzed (Borgatti et al., 2009). First, similarities such as location (e.g. same spatial or temporal space), membership (e.g. same club) or attribute (e.g. same attitude) form a type of tie. Second, there are social relations. These include kinship, role (e.g. friend of), affective (e.g. likes someone) or cognitive relations (e.g. knows someone). Third, interactions such as social support or sexual intercourse are investigated. The final type of tie are flows, which can refer to information or resources.

SNA studies can utilize two distinctive, major research designs. If the interest is in analyzing a social structure and the dependencies created for the actors in them, the study is socio-centric and investigates formation or effects of a complete network. If the research compares social actors that are characterized by their social environment, ego-centric network analysis is performed. In an ego-network, the 'ego' is the actor of interest (and a member of the population sample under scrutiny) and the other actors in the network are called 'alters'. Their presence and relationships merely serve to characterize ego.

Another crucial aspect is whether the study aims to identify networks and latent structures that have evolved unknowingly/informally (e.g. networks of information flow or friendship) or purposefully/formally (e.g. inter-organizational alliances, school classes, sport clubs). Contemporary SNA studies typically employ two strategies of boundary setting (Knoke \& Yang, 2008). With the realist strategy, the boundaries of the network are defined by the judgment of the network members. With the nominalist strategy, the researcher defines the boundaries. More than in traditional attributive surveys, network data can be very sensitive to missing information. Observations are likely to be dependent by design, and the lack of a single important actor can fundamentally alter the analytic reconstruction of a network.

Finally, one-mode and two-mode networks have to be distinguished. One mode networks consist of only one type of linked units, whereas, in two-mode networks links are constructed indirectly via two sets of units (e.g. persons attending an event).

\section{Methodological concepts}

The concepts of SNA are accompanied by various techniques. Based largely on graph theory and linear algebra, these techniques represent a powerful toolkit to analyze networks. Here, we only give an overview of the main categories of analytic methods. For a detailed introduction, see any of the recent textbooks in social network analysis (e.g. Scott, 2012; Hennig, Brandes, Pfeffer, \& Mergel, 2012; Borgatti, Everett, \& Johnson, 2013). 


\section{Centrality}

Positions in a network may be associated with different advantages or disadvantages for the actors that occupy them. There are four commonly utilized indicators that capture distinct aspects of centrality. Degree centrality counts the number of (direct) ties of an actor. It provides a measure of activity or direct influence. Closeness centrality considers the direct and indirect relationships with all other actors. An actor is close to another if few ties are required to move from one to the other through the network. Closeness is a measure of access, efficiency, or independence from intermediaries. Betweenness centrality measures the actor's control over the indirect relationships of others via its presence in connections between them. Eigenvector centrality considers actors important if they have direct ties to important actors. Variants too numerous to survey here have been proposed (Brandes \& Erlebach, 2005). At the network level of analysis, it may be of interest to assess to which degree a network is centralized (Freeman, 1979), that is the skewness of the distribution of the individual actors' centrality scores.

\section{Cohesion}

The prototypical group-level analysis is the identification of cliques. Cliques are groups of actors in which everyone has a tie with everyone else. Since such maximally-cohesive subgraphs are rare, empirical studies will often relax this concept, allowing for some missing ties. Clustering or community detection refers to the decomposition of a network into groups that are internally cohesive but sparsely connected among each other. Again, various formal criteria are used to make these concepts concrete, and to obtain disjointed, overlapping, or hierarchically-nested groups. A simple measure of group's cohesion is the density of its internal ties. Density is the ratio between existing and potential ties. A clique has the maximum possible density of one. Density is also a network-level indicator, but since the number of possible ties grows quadratically with the number of actors, the average degree of actors is usually easier to interpret (Hennig, Brandes, Pfeffer, \& Mergel, 2012).

\section{Roles}

A complementary concept of simplifying network structure by grouping actors is based on the similarity of network positions, rather than cohesion. Actors possessing identical ties to identical actors are considered to be structurally equivalent. Actors related in the same way to equivalent, but non-identical others have regular equivalence. These are network counterparts of roles, and in many cases it may be preferable to settle for role similarity rather than equivalence. Both cohesion-based partitioning and role assignment generalize to a technique called blockmodelling (Doreian, Batagelj, \& Ferligoj, 2004). In blockmodelling, actors are partitioned into groups (i.e. the blocks) subject to constraints on the patterning of ties within and between these groups.

\section{Macro structure}

In addition to network-level characteristics such as density or the notorious properties of scale-freeness (i.e. power-law degree distribution; see Clauset, Shalizi, \& Newman, 
2009) or small-worldliness (i.e. sparse and locally cohesive networks with low average distance; see Schnettler, 2009), there are at least two genuinely interesting macro configurations. The first is a division of the actors into a single, tightly-knit core and a loosely connected periphery which may or may not be attached to the core (Borgatti \& Everett, 1999). The other commonly investigated macro structure is whether the relationships of actors reflect a hierarchy, rather than a more horizontal organization (Krackhardt, 1994).

\section{Micro structure}

Networks can also be characterized by the presence, or absence, of small template configurations such as triangles (Holland \& Leinhardt, 1976). These configurations form the basis for stochastic network models (Goldenberg, Zheng, Fienberg, \& Airoldi, 2009; Snijders, 2011; Lusher, Koskinen, \& Robins, 2013). In cases where they are unexpectedly frequent, they are sometimes referred to as motifs (Milo et al., 2002).

\section{Goals and applications}

On various levels of analysis, the above network concepts and measures are used to address specific versions of three principal questions in network analyses (Figure 1):

1. Where do certain social network structures come from? (network formation)

2. What is the structure of certain social networks? (network description)

3. What are the consequences of certain social network structures? (network effects)

While studies of network effects consider social networks as antecedents or conditions, networks are the outcomes or consequences in studies of network formation (Borgatti et al., 2009; Brass et al., 2004; Raab \& Kenis, 2009). In both cases and also in descriptive studies, assessment of features and peculiarities of a network is a basic requirement (i.e. network description). Even without any explanatory aspiration, network description is extremely valuable, for example, in case studies and comparative analyses.

Causal relationships between networks and other phenomena usually require a theoretically informed decision that specifies the independent and dependent variable. Actor similarity (e.g. age, gender, ethnicity, or education) can foster communication

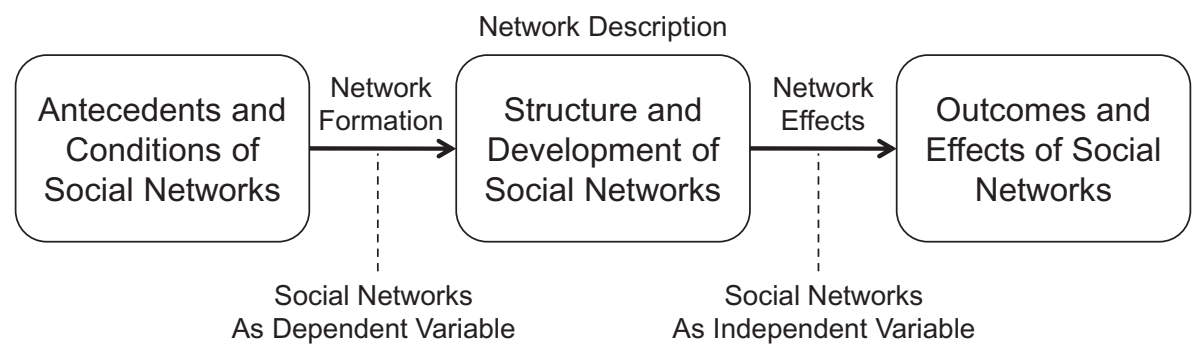

Figure 1. Basic questions in social network research. 
and the building of reciprocal trust. This creates a structural phenomenon called homophily (i.e. the tendency for actors to associate with similar others) (McPherson, Smith-Lovin \& Cook, 2001). If, on the other hand, networks are the independent variable, their features are supposed to influence certain outcomes. This is usually the case in research on social capital, where it is assumed that, for example, individual success (e.g. getting a job, better health) can be explained by access to resources. Social networks often serve as intermediary variables as in the famous study on the strength of weak ties by Granovetter (1973). He first argued that networks form in a way that ties between different groups are never strong (network formation). Second, he found that novel information (e.g. employment opportunities) arrives via weak ties (network effect). Alternatively, studies in the co-evolution of network structure and actor behaviour use a longitudinal approach to differentiate social influence (i.e. network effects on behaviour) from social selection (i.e. network formation based on behaviour).

\section{Limitations}

Because the units of observation are dyads that share nodes with other dyads, SNA faces a number of unique challenges. The above-mentioned problem of boundary specification is inherent and different from sampling issues in other empirical research. Moreover, the characteristics of relationships are often less precisely captured than actor attributes. This problem can lead to inappropriate homogeneity assumptions. Friendship, for instance, is a complex social relationship that, depending on the analytical focus, may not be well categorized as being symmetric, present or absent, or rated.

In survey-based SNA, researchers often have to deal with incomplete data sets due to non-responses. While there are ways to deal with missing data in SNA (e.g. Borgatti, Everett, \& Johnson, 2013; Kossinets, 2013), incomplete data remain a major challenge in survey-based SNA.

Finally, a major issue in current practice of SNA is the treatment of analytic tools as black boxes that are deemed applicable across diverse settings based on abstract structural interpretations. Creating links between substantive theory and formal analysis can be difficult because mathematical procedures are complex and thus laden with implicit assumptions.

In summary, SNA is widespread in the social sciences and has broadened substantially the analytic capacity of the social sciences. The relational perspective argues that social actions and processes are both constrained and facilitated by social ties. Social actors are embedded in 'webs of social relations and interactions' (Borgatti et al., 2009, 892). This embeddedness in networks does not only impose constraints, but provides also opportunities. Networks facilitate access to resources and organize the infrastructure for exchange, communication and cooperation. Norms are acquired in, and generated through, networks. SNA focuses on the relational nature of social structure rather than categories attributed to independent social units. As such, SNA represents a method to advance the substantive understanding of structures and processes constructed through or resulting in relations among social actors. 


\section{The network perspective in sport research}

Although the network perspective is relatively new in sport research, its basic ideas feature in a number of classic studies. Possibly the best known example of this kind is Grusky's early study on the effects of formal team structure on managerial recruitment in baseball organizations (1963). He showed that professional baseball players in a central position (i.e. infielders and catchers) were more likely to be recruited as team managers than less central players (i.e. outfielders and pitchers). Following Grusky's approach, several studies picked up this centrality hypothesis. Loy, Curtis, and Sage (1978) reviewed several replication studies and showed that Grusky's basic idea that occupants in central positions are over-represented in leadership positions is also evident in North American basketball, football and hockey teams. These findings were confirmed across professional, intercollegiate and interscholastic teams. In an extension of Grusky's 'theory of formal structure', Loy and McElvogue (1970) showed that African-American players are more likely to hold peripheral positions in baseball teams. This finding was also confirmed in other contexts such as English soccer ${ }^{2}$ (Norris \& Jones, 1998). Although, these studies did not apply the formal methods of SNA, they utilized the basic idea of network research that either actor similarity (e.g. race) influences structural positions in networks (i.e. players' positions) or that structural positions influence recruitment to leading positions (i.e. individual success).

In the early 1990s, Nixon (1992) utilized SNA ideas to develop a framework for understanding the risk culture of athletes who play with pain and injuries. Nixon introduced the term sportsnet to describe athletic subcultures that are characterized not only by a system of interaction between a group of people in sport but also by shared meaning, symbols, rituals, norms, etc. This study provides an excellent explanation how structural embeddedness constrains athletes' behaviour when dealing with pain and injuries. However, his analysis remains at the conceptual level with no explicit reference to SNA methods. In a subsequent paper, Nixon broadened his approach to provide an overview 'of the potential value of a structural social network approach' (1993, 315). Although Nixon did not apply any formal methods of SNA, his work stands out as the first significant contribution to social network research in the sports domain, drawing on a consistent theoretical approach of the social network perspective (Roderick, 1998). ${ }^{3}$

Another area that adopted network-related approaches relatively early is the field of organizational behaviour and management in sport. Cousens and Slack (1996) analyzed inter-organizational networks within North America's major professional sports leagues. In another early paper, Erickson and Kushner (1999) drew on network theory to develop a theoretical framework to explain the organizational structure of sport events. Wolfe, Meenaghan, and O'Sullivan (2002) investigated the 'sports network' between governing bodies of sport, mass media and sponsors with regard to issues of power and dependency. The question of inter-organizational power was also the subject of a study on the process of expansion of the Victorian Football League in Australia (Dickson, Arnold, \& Chalip, 2005). In 2008, a special issue of the International Journal of Sport Management and Marketing (Dickson \& Cousens, 2008) was dedicated to 'Sport Organisations and Inter-Organisational Relationships'. Articles within this issue highlighted several aspects and areas of analysis drawing on network-related concepts 
in the field of organizational behaviour and sport management. Other topics that were addressed in this field include social capital and its creation in community networks through sport events (Misener \& Mason, 2006), determinants of collaborative relation formation in a network around a high-performance training centre (Babiak, 2007), and functional mechanisms of networks in regional sport tourism (Wäsche \& Woll, 2010). These are just a few examples demonstrating that the basic ideas of structural analyses and network theory are present in the sport management literature (see also Quatman \& Chelladurai, 2008a). However, none of these studies systematically applied the methods of SNA as discussed previously.

Only over the past few years, sport researchers have adopted network-analytic methods. While Nixon (1993) provided the first systematic overview of potential uses of SNA, two articles provided detailed introductions to methods of SNA and point to potential applications in sport research. Quatman and Chelladurai (2008b) describe SNA research from a sport management perspective. They discuss philosophical assumptions of social network theory, and explain various methods and concepts of network analysis. Based on the finding that no studies in the field of sport management have fully utilized methods of SNA, they point to the usefulness of SNA to stimulate interdisciplinary research in various sports-related fields. Lusher, Robins, and Kremer (2010) also discuss various methods and concepts of SNA and focus on possible applications for the analysis of individual and group behaviour in team sports. Similar to Grusky (1963), they point to team structure as an explanatory variable. But, differently to Grusky, they consider team structure in terms of friendship ties and social influence of players and not as relations of game-immanent exchange. Both introductions show that sport researchers have become aware of SNA methods. However, to date methods of SNA have sparsely been applied to sport research (e.g. Fransen et al., 2015; Wäsche, 2015)

To summarize, the network perspective and related ideas and concepts were adopted quite early by sport researchers. But, it was only in the 1990s that a substantial discussion and inclusion of approaches based on the network perspective began. While the studies made use of network-related concepts and ideas, most did not apply the methodological tools that SNA provides. However, SNA methods are increasingly prevalent within sport-related research. In the following sections, studies applying the methods of SNA are reviewed systematically.

\section{Systematic review}

\section{Methods}

The basis of this systematic review is a comprehensive search of relevant studies within defined boundaries. After their identification, these studies are evaluated and categorized. The purpose of this review is to explore and exemplify the scope of SNA applications in sport research to inform our ideas about present and future uses. We do not aim to produce an exhaustive overview of the literature. Rather, our goal is to systematically assess the utility of SNA for sport research and to produce a typology to promote and guide future research.

For inclusion in the review, two thematic elements were required: sport and SNA. Only articles with a substantive consideration of sport were included. Studies that 
considered sport just as a minor aspect or used sport-related phenomena only for exemplary purposes (e.g. Masuda \& Konno, 2006; Steen, Hayasaka, Joyce, \& Laurienti, 2011, Ziakas \& Costa, 2010) were excluded.

To grasp all relevant aspects of the field to analyze, we did not only consider active sport participation but also spectatorship and sport's organizational structures. Articles on physical activity in the context of preventive medicine, health promotion, health behaviour and public health were excluded from this review. These studies refer to aspects that go beyond the scope of our research. ${ }^{4}$ The second criterion was the utilization of the formal, quantitative methods of SNA. Since structuralism and relational analyses are widespread in the field of humanities, social and natural sciences (Wellman \& Berkowitz, 1988), we required the use of methods as described in SNA textbooks such as Borgatti, Everett, and Johnson (2013), Henning, Brandes, Pfeffer, and Mergel (2012), Knoke and Yang (2008), Scott (2000), or Wasserman and Faust (1994). Apart from these thematic elements, we only included studies of social networks comprising social actors or units such as persons, groups, teams, organizations or social artifacts produced by social actors (e.g. concepts, ideas or publications) (Babbie, 1992). The final inclusion criterion was that the article had been published in a peer-reviewed, English-language, academic journal.

After establishing the four-phase inclusion criteria, we searched for articles in three electronic databases - Web of Science, Scopus and SPORTDiscus - to ensure expansive coverage. Articles published up to the end of 2012 were considered. ${ }^{5}$ For the search, network-related terms were combined with terms related to sport, as well as globally popular sport disciplines and major sport events (see Table 1).

These sport-related terms were also searched for in three social network journals Connections, Social Networks and Journal of Social Structure. Wildcard characters were applied to take into account different spellings and plural forms of the search terms. The results were analyzed concerning their relevance for the field of interest of this review. Based on the abstracts of these articles, 49 potentially relevant studies were identified. Subsequently, a snowball search was undertaken based on the reference list of the retrieved articles. This led to the identification of four more articles. After a thorough reading of all 53 selected articles, 27 articles were excluded because they did not meet all of the inclusion criteria. The final sample consists of 26 articles from 20 different journals (refer Table 2).

Each article that met the inclusion criteria was then indexed. A summary for each article was produced comprising topic and purpose of the study, type of network analysis (i.e. descriptive or explanatory), data collection, methodological concepts of SNA, types of ties and nodes and main results. The categorization facilitates a comparison

Table 1. Search terms. ${ }^{a}$

\begin{tabular}{ll}
\hline Network-related terms & \multicolumn{1}{c}{ Sports-related terms } \\
\hline 'network analysis' & 'sport', 'physical activity', 'physical education', 'outdoor \\
'network approach' & education', 'outdoor recreation', 'soccer', 'football', \\
'network method' & 'hockey', 'rugby', 'cricket', 'baseball', 'basketball', \\
& 'volleyball', 'golf', 'tennis', 'olympic' \\
\hline
\end{tabular}

${ }^{a}$ Search terms were combined through the Boolean operator AND. 
Table 2. Identified articles of systematic research.

\begin{tabular}{|c|c|c|c|}
\hline Authors & Year & Title & Journal \\
\hline Agulló-Calatayud et al. & 2008 & $\begin{array}{l}\text { Consumption of anabolic steroids in } \\
\text { sport, physical activity and as a } \\
\text { drug of abuse: An analysis of the } \\
\text { scientific literature and areas of } \\
\text { research. }\end{array}$ & British Journal of Sports Medicine \\
\hline Bothner et al. & 2012 & $\begin{array}{l}\text { How does status affect performance? } \\
\text { Status as an asset vs. status as a } \\
\text { liability in the PGA and NASCAR. }\end{array}$ & Organization Science \\
\hline Breznik \& Batagelj & 2012 & $\begin{array}{l}\text { Retired matches among male profes- } \\
\text { sional tennis players. }\end{array}$ & $\begin{array}{l}\text { Journal of Sports Science and } \\
\text { Medicine }\end{array}$ \\
\hline Bruner et al. & 2010 & $\begin{array}{l}\text { An appraisal of athlete development } \\
\text { models through citation network } \\
\text { analysis. }\end{array}$ & Psychology of Sport and Exercise \\
\hline Cobbs & 2011 & $\begin{array}{l}\text { The dynamics of relationship market- } \\
\text { ing in international sponsorship } \\
\text { networks. }\end{array}$ & $\begin{array}{l}\text { Journal of Business \& Industrial } \\
\text { Marketing }\end{array}$ \\
\hline Cousens et al. & 2012 & $\begin{array}{l}\text { Strategies to increase sport participa- } \\
\text { tion in Canada: The role of a coor- } \\
\text { dinated network. }\end{array}$ & $\begin{array}{l}\text { International Journal of Sport } \\
\text { Management and Marketing }\end{array}$ \\
\hline Duch et al. & 2010 & $\begin{array}{l}\text { Quantifying the performance of indi- } \\
\text { vidual players in a team activity. }\end{array}$ & PLOS ONE \\
\hline Fewell et al. & 2012 & $\begin{array}{l}\text { Basketball teams as strategic } \\
\text { networks. }\end{array}$ & PLOS ONE \\
\hline Grund & 2012 & $\begin{array}{l}\text { Network structure and team perform- } \\
\text { ance: The case of English Premier } \\
\text { League soccer teams. }\end{array}$ & Social Networks \\
\hline Hambrick & 2012 & $\begin{array}{l}\text { Six degrees of information: Using } \\
\text { social network analysis to explore } \\
\text { the spread of information within } \\
\text { sport social networks }\end{array}$ & $\begin{array}{l}\text { International Journal of Sport } \\
\text { Communication }\end{array}$ \\
\hline Jessop & 2006 & $\begin{array}{l}\text { A measure of competitiveness in } \\
\text { leagues: A network approach. }\end{array}$ & $\begin{array}{l}\text { Journal of the Operational } \\
\text { Research Society }\end{array}$ \\
\hline Kooij et al. & 2009 & $\begin{array}{l}\text { The Dutch soccer team as a social } \\
\text { network. }\end{array}$ & Connections \\
\hline Leifer & 1990 & $\begin{array}{l}\text { Enacting networks: The feasibility of } \\
\text { fairness. }\end{array}$ & Social Networks \\
\hline Leung et al. & 2011 & $\begin{array}{l}\text { A social network analysis of overseas } \\
\text { tourist movement patterns in } \\
\text { Beijing: The impact of the Olympic } \\
\text { Games. }\end{array}$ & $\begin{array}{l}\text { International Journal of Tourism } \\
\text { Research }\end{array}$ \\
\hline Love \& Andrew & 2012 & $\begin{array}{l}\text { The intersection of sport manage- } \\
\text { ment and sociology of sport } \\
\text { research: A social network } \\
\text { perspective. }\end{array}$ & Sport Management Review \\
\hline Mukherjee & 2012 & $\begin{array}{l}\text { Identifying the greatest team and } \\
\text { captain: A complex network } \\
\text { approach to cricket matches }\end{array}$ & $\begin{array}{l}\text { Physica A: Statistical Mechanics } \\
\text { and Its Applications }\end{array}$ \\
\hline Onody \& De Castro & 2004 & $\begin{array}{l}\text { Complex network study of Brazilian } \\
\text { soccer players. }\end{array}$ & $\begin{array}{l}\text { Physical Review E - Statistical, } \\
\text { Nonlinear, and Soft Matter } \\
\text { Physics }\end{array}$ \\
\hline Passos et al. & 2011 & $\begin{array}{l}\text { Networks as a novel tool for studying } \\
\text { team ball sports as complex social } \\
\text { systems. }\end{array}$ & $\begin{array}{l}\text { Journal of Science and Medicine } \\
\text { in Sport }\end{array}$ \\
\hline Quatman \& Chelladurai & $2008 a$ & $\begin{array}{l}\text { The social construction of knowledge } \\
\text { in the field of sport Management: } \\
\text { A social network perspective. }\end{array}$ & Journal of Sport Management \\
\hline Radicchi & 2011 & $\begin{array}{l}\text { Who is the best player ever? A com- } \\
\text { plex network analysis of the his- } \\
\text { tory of professional tennis. }\end{array}$ & PLOS ONE \\
\hline Saavedra et al. & 2010 & $\begin{array}{l}\text { Mutually-antagonistic interactions in } \\
\text { baseball networks. }\end{array}$ & $\begin{array}{l}\text { Physica A: Statistical Mechanics } \\
\text { and its Applications }\end{array}$ \\
\hline
\end{tabular}


Table 2. Continued

\begin{tabular}{llcc}
\hline Authors & Year & Title & Journal \\
\hline Sallent et al. & 2011 & $\begin{array}{c}\text { Exploring the legacy of sport events } \\
\text { on sport tourism networks } \\
\text { Ranking patterns in college football's } \\
\text { BCS selection system: How confer- } \\
\text { ence ties, conference tiers, and } \\
\text { the design of BCS payouts affect } \\
\text { voter decisions. }\end{array}$ & $\begin{array}{c}\text { European Sport Management } \\
\text { Quarterly } \\
\text { Social Networks }\end{array}$ \\
Seevers et al. & 2011 & $\begin{array}{c}\text { Performance implications of a retail } \\
\text { purchasing network: The role of } \\
\text { social capital. }\end{array}$ & Journal of Retailing \\
Warner et al. & 2010 & $\begin{array}{c}\text { Team dynamics: A social network } \\
\text { perspective. } \\
\text { Zachary }\end{array}$ & An information flow model for con- \\
flict and fission in small groups. & Journal of Sport Management \\
\hline
\end{tabular}

of the studies and provides an overview of the current state of research SNA and sport.

\section{Results}

The results of this systematic review are summarized and categorized in Table 3. The categorization of the identified articles provides a synopsis of SNA research in the field of sports. Before we discuss the studies in more detail, it is noteworthy to consider the period and years of publication. As can be seen in Table 2, most of the studies were published at the end of the searched time period. Nineteen of the 26 identified studies were published during the last three years of our review (2010-2012), with nine of them published in 2012. The studies by Zachary (1977) and Leifer (1990) are clear outliers. $^{6}$

Of the 20 journals to have published the studies, only nine were sport-related. The other 11 journals are focused on social networks, physics, business, organization theory, methodology, anthropology, tourism, and science (see Table 2). Six of the studies were published in social network journals. Whilst this confirms the interdisciplinary nature of sport research, the fact that most of the research is published in non-sport journals suggests that sport-related SNA research is yet to reach full maturity.

In the following paragraphs, the 26 identified articles will be discussed in thematic order. Four major domains are evident: (a) sport-related scientific literature, (b) social structure of sport organization, (c) sport management, and (d) sport performance.

\section{Sport-related scientific literature}

Four of the identified studies applied SNA to analyze bibliometric data. To study the structure and development of sport-related scientific knowledge, one citation network analysis and three co-authorship analyses were conducted. Agulló-Calatayud, GonzálezAlcaide, Valderrama-Zurián, and Aleixandre-Benavent (2008) investigated co-authorship networks on studies of anabolic steroids consumption in sport. The study identified the most prolific authors, the most relevant journals, and mapped clusters of collaborating authors and a network of related concepts. Quatman and Chelladurai (2008a) 


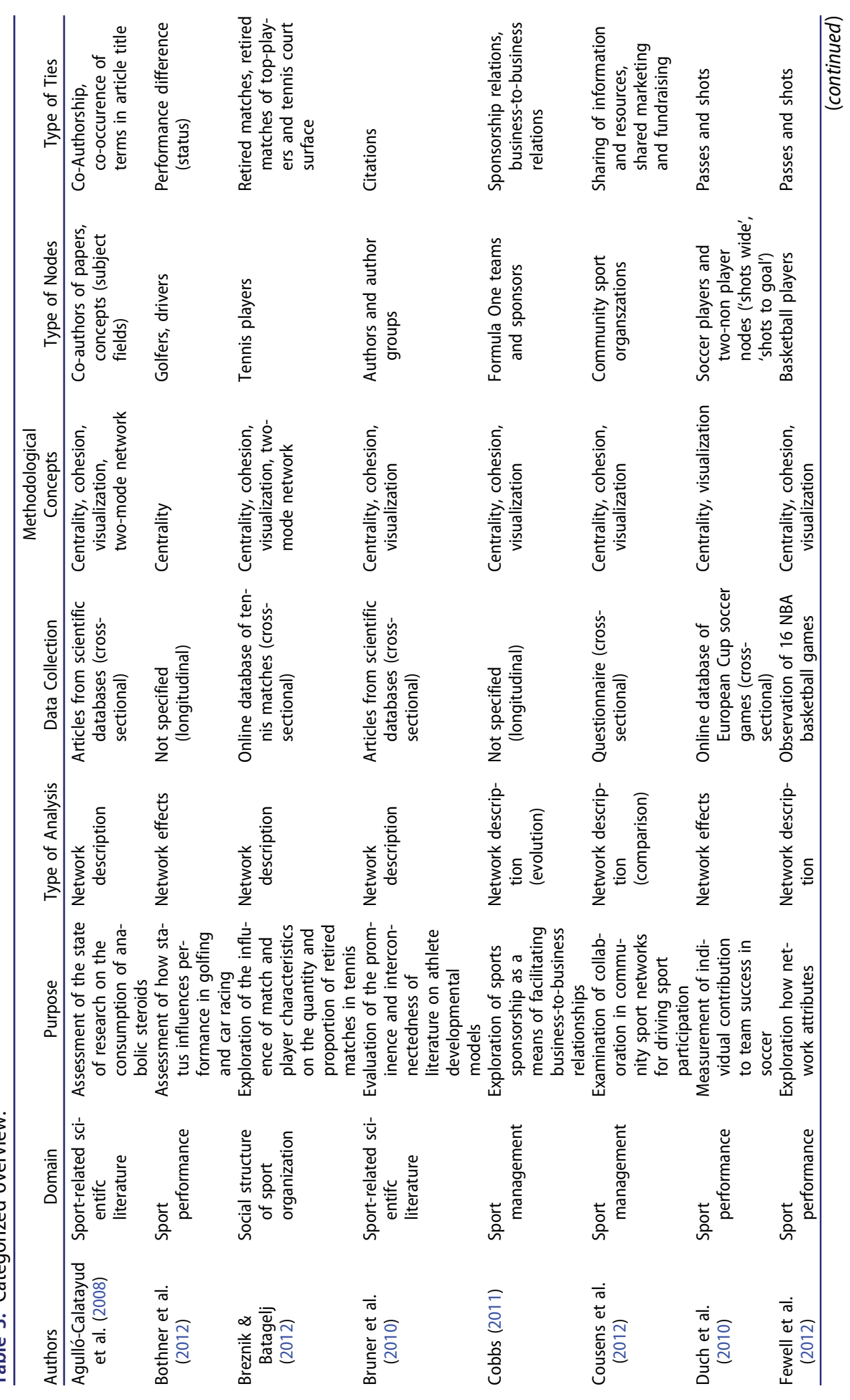




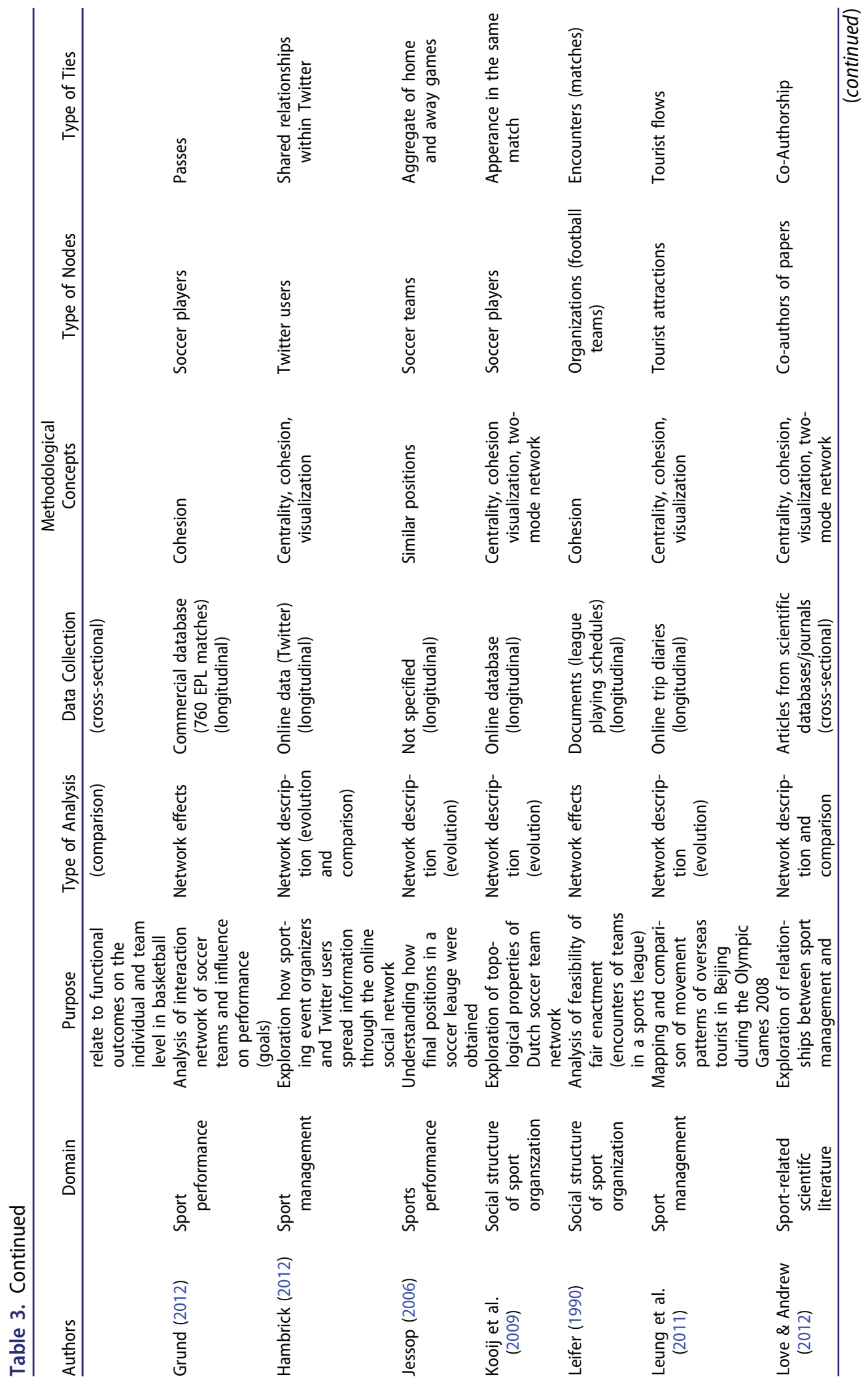




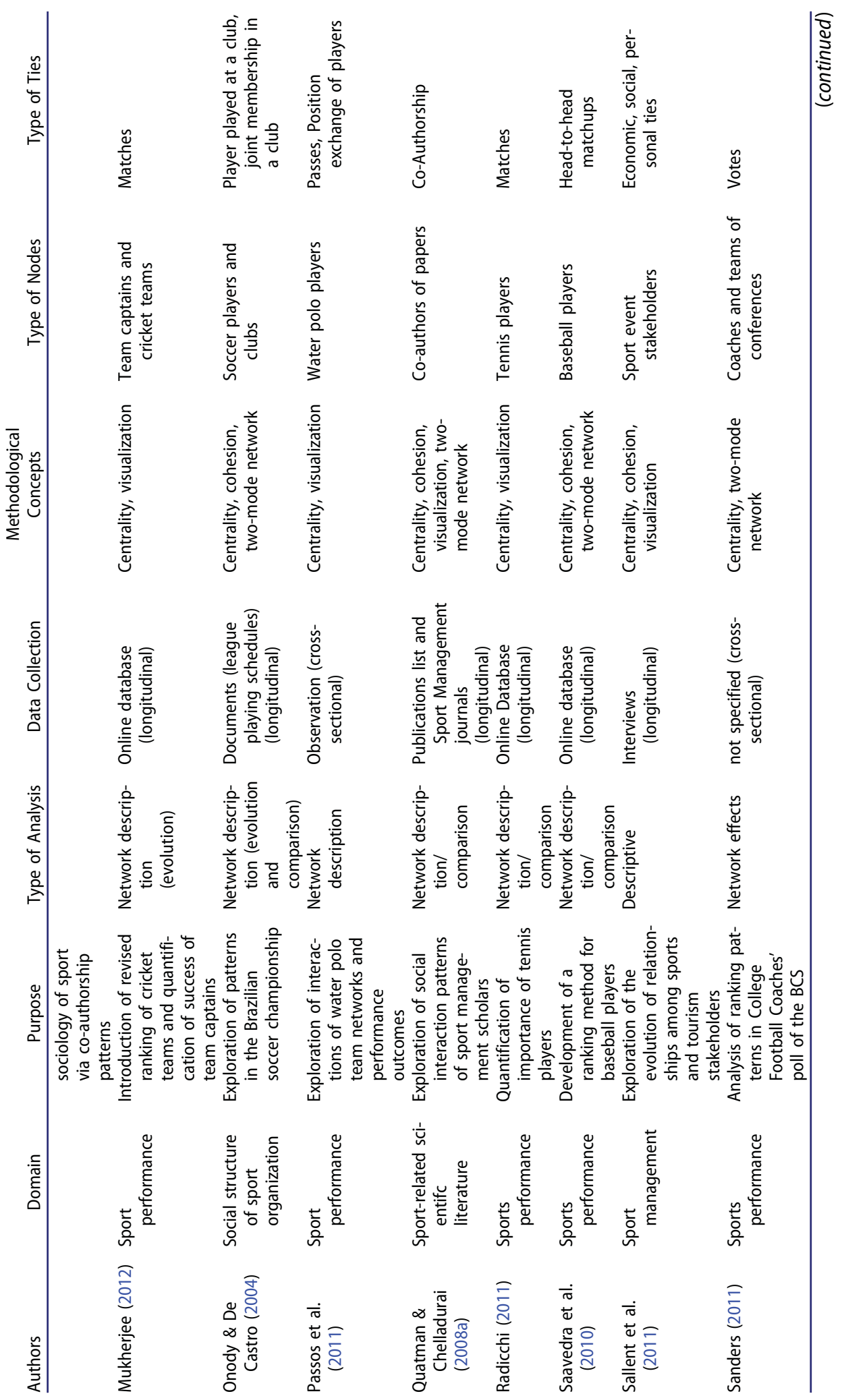




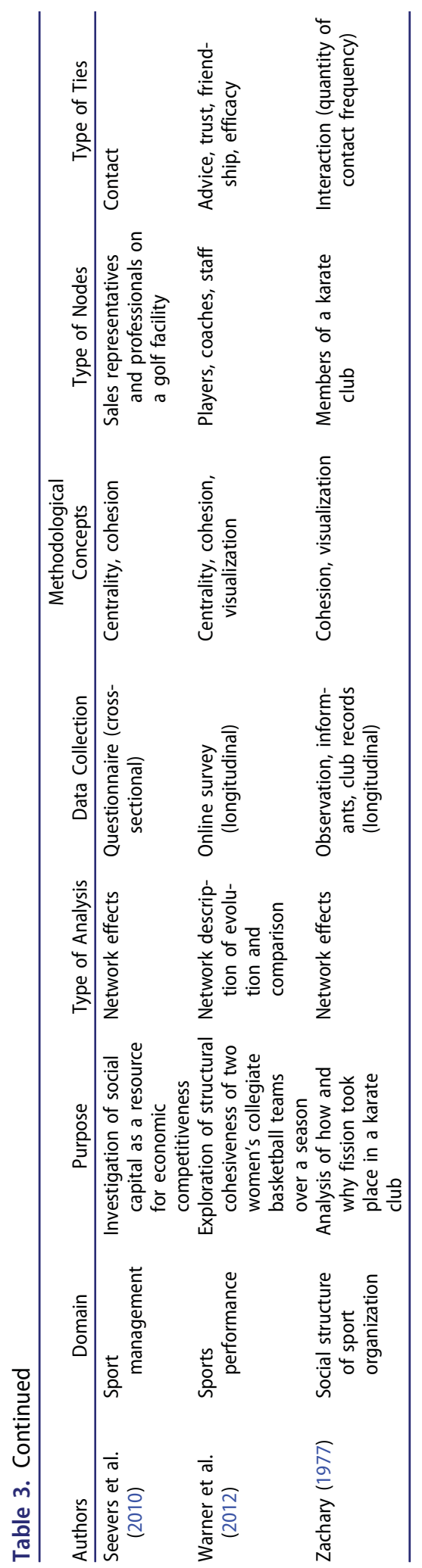


reconstructed the evolution of the field of sport management research through measuring and mapping of co-authorship networks from different time periods. They concluded that the field of sport management shows the evolution pattern of a new scientific field, characterized by a few isolated groups in the beginning that evolved into a more cohesive and consistent network. Love and Andrew (2012) analyzed co-authorship patterns in three sport management and three sport sociology journals. They showed that the connections between the two fields of research - sport management and sociology of sport - are rather weak, while collaboration is more common in sport management. In a citation network analysis, Bruner et al. (2010) evaluated the interconnectedness of sport psychology studies concerning models of athlete development. Utilizing the centrality concept, the most influential models were identified. Furthermore, two cohesive subgroups with only little connection, representing two schools of thought, with limited knowledge transfer were revealed. This indicated a deficit in the body of knowledge.

\section{Social structure of sport organization}

In five studies the social structure of sport organizations such as sport leagues, clubs or associations was analyzed. Leifer (1990) used network analysis to demonstrate via an experiment, the complexity of ensuring a fair playing schedule (i.e. equal total encounters of actors and equal number of home and away games) for the National Football League. Onody and De Castro (2004) constructed a two-mode network of 13,411 Brazilian soccer players. Players were considered connected if they played at the same club at the same time. Several structural patterns were identified, including a 'small world network'. Similarly, Kooij et al. (2009) explored the network of Dutch national soccer team players that had appeared in the same match. Besides a network description it was also concluded that the network is a 'small world'.

In the field of tennis, Breznik and Batagelj (2012) examined the influence of match and player characteristics on the proportion of retired matches in professional tennis tournaments. Accordingly, the incidence of retired matches was higher on hard and clay courts, compared to grass and carpet courts, and the proportion of retired matches is inversely related to the tournaments status. The study by Zachary (1977) is the oldest of all studies on structural organization and probably the most popular one since its database is freely available and has been widely used to test algorithms for community detection (Newman, 2006). Based on an anthropological approach, Zachary (1977) observed members of a university karate club for a three-year period. A social conflict in the club led to a split into two groups. Based on weighted friendship ties and a model of information flow, he was able to explain coalition formation and the fission within the karate club.

\section{Sport management}

In the domain of sport management six studies were identified, all of which were published after Quatman and Chelladurai's (2008b) call on integrating the network theory and analysis for a greater understanding of sport management topics. In a relationship marketing study, Cobbs (2011) investigated the network of relations between Formula 1 teams and their sponsors. He emphasized the utility of SNA to assess 
sponsorship networks with regard to their potential to build business-to-business relationships among sponsors. Cousens et al. (2012) investigated collaboration within a community-based basketball and a swimming network to understand network integration. Seevers et al. (2010) analyzed the economic performance in a golf retail network. Drawing on the concept of social capital, the results suggest that social capital leads to a better economic performance. The study of Hambrick (2012) explored how two bicycle race organizers used Twitter to promote their events. The remaining two studies deal with sport event tourism. One study demonstrated that a sport tourism network became more cohesive through a local sport event (Sallent, Palau, \& Guia, 2011). The second sport tourism study mapped and compared movement patterns of overseas tourists in Beijing during the 2008 Olympic (Leung et al., 2011).

\section{Sport performance}

In total, 11 studies investigated the performance of individual athletes and teams. Three studies pursued the goal of developing rankings through SNA. Radicchi (2011) created a network using matches between players as ties for the development of a method to rank the best tennis players in history. The database consisted of more than 130,000 professional tennis matches. In a similar approach, Mukherjee (2012) developed an overall ranking for cricket teams and captains based on all played matches. Saavedra et al. (2010) produced seasonal and whole-career rankings of Major League Baseball players using a network structure of head-to-head matchups between pitchers and batters. In a different approach, Sanders (2011) created affiliation matrices to determine how structural aspects influenced how college football coaches ranked teams in the American Bowl Championship Series.

Four studies utilized ball movements as ties to examine patterns of athlete interaction. The first to operationalize a sport game in this way were Duch et al. (2010), who sought to explain team success at the European Soccer Cup 2008. The authors showed that 'flow centrality' can be applied to analyze individual and team outcomes. Furthermore, network visualizations of individual matches provided interesting insights to passing patterns among the players of a succeeding or losing team. In another study on soccer teams, Grund (2012) analyzed athlete interaction within soccer teams and their influence on performance. Using 760 English Premier League games he found that a high passing rate (i.e. high level of interaction) was associated with an increased team performance and that more centralized interaction patterns were associated with low team performance. Fewell et al. (2012) focused on athlete interactions in basketball. In an analysis of 16 National Basketball Association games they identified several aspects of offensive strategies. Unpredictability and connectedness across players was associated with a better performance. Passos et al. (2011) analyzed interactions (i.e. passes and position exchanges) among players of two water polo teams. They observed team-level attack strategies that explain performance outcomes. Warner et al. (2012) explored structural cohesiveness of two women's collegiate basketball teams over a season. In contrast to the previously presented studies, they did not consider ball movements. Rather they used advice, trust, friendship and efficacy as ties to 
assess cohesiveness. Their results suggest that an increase in cohesiveness based on trust and efficacy fosters team performance while an increased cohesion based on friendship and advice has a negative effect on performance.

In another attempt to assess the performance of soccer teams, Jessop (2006) analyzed nine seasons of the English Premier League. Teams were grouped into blocks of similar performance utilizing blockmodelling. While Jessop demonstrated the applicability of blockmodels to describe team performance within a league, the analyzed networks resembled random networks with little structure. Finally, Bothner et al. (2012) analyzed the causal relationship between status (based on earlier performance) and its influence on the performance of motorsport drivers and professional golfers. They found that status had a positive impact on performance. However, once a high status was reached, performance declined.

\section{Discussion}

The results of our review shed light on the state of research investigating social structure in sport through SNA. Our first conclusion is that the application of SNA in sport research is a rather young and emergent phenomenon. Most of the identified studies were published in the last three years of the analyzed time period. Additionally, the majority of the studies are exploratory or descriptive, aiming to understand, describe and compare networks and their evolution. The studies focus on the 'what' of network structures rather than asking for conditions or consequences of networks with the aim of understanding the 'why' (Figure 1). These types of analyses indicate that the investigated topics and phenomena are relatively new and are not well understood (Babbie, 1992). However, we note that there are also studies of an explanatory nature.

A broad range of data collection techniques and methodological concepts are evident. Different measures of centrality at the actor-level of analysis were found in almost all of the studies. Also, the measurement of network density as a measure of cohesion at the network or group level of analysis was widely used. Various network visualizations revealed insightful patterns. Other less frequently utilized techniques are the analysis of subgroups or clusters and macro structures such as small-worldliness. Concerning the units of analysis, nodes were more likely to represent individuals rather than organizations or social artifacts. While individuals such as academics or sales representatives are not specific to sport, the players, athletes, or coaches are. The same is true for sports teams or clubs operationalized as organizational actors of social networks. Correspondingly, there are types of ties that are sport-specific. These include passes and shots in ball games, team encounters in matches, pairs of home and away games, joint membership in a team or individual players' matchups (Table 4).

While data were often collected through questionnaire-based surveys, the review revealed that electronic databases are a very valuable source for SNA in sport research. As bibliometrics make use of scientific databases for their analyses, studies about sport performance and structural patterns of the organization of sport benefit from extensive and often easily accessible statistical data. Moreover, since these datasets often consist of records of previous years and decades, they provide the opportunity to analyze longitudinal data. Another noteworthy aspect is the focus on whole networks. Ego-centric network studies appear to be underrepresented. 
Table 4. Sports-specific network data.

\begin{tabular}{lll}
\hline & \multicolumn{1}{c}{ Individual level } & \multicolumn{1}{c}{ Group/organizational Level } \\
\hline Actors & Athletes, coaches & $\begin{array}{c}\text { Sports teams, clubs, providers } \\
\text { Ties }\end{array}$ \\
& $\begin{array}{c}\text { Passes and shots, matches between indi- } \\
\text { viduals, joint membership in teams, } \\
\text { individual match-ups, performance dif- } \\
\text { ference, position exchange of players }\end{array}$ & $\begin{array}{c}\text { Aggregates of home and away games, } \\
\text { matches between teams }\end{array}$ \\
& & \\
\hline
\end{tabular}

The majority of analyses addresses sport performance. Here, two major approaches can be differentiated. Most studies focus on the ranking or results of athletes or teams (Bothner et al., 2012; Jessop, 2006; Mukherjee, 2012; Radicchi, 2011; Saavedra et al., 2010; Sanders, 2011; Warner et al., 2012). The other approach is focused on gamebased interactions of players within a team (Duch et al., 2010; Fewell et al., 2012; Grund, 2012; Passos et al., 2011). In these studies, interactions (i.e. ball passes) are rulebased elements of sport games. These studies analyze interaction patterns within games to explain the performance of a single player or the whole team. Similarly, mainly sport-specific outcomes stand in the centre of studies concerned with structural patterns in sport organization (Breznik \& Batagelj, 2012; Kooij et al., 2009; Leifer, 1990; Onody \& De Castro, 2004). However, it was not performance but structural features such as the number and proportion of retired tennis matches, path length among connected players in two-mode networks, or equitable playing schedules in a sport league that were analyzed.

The results of the review enable us to develop a conceptual typology of SNA in the field of sport. In total, six different types can be derived (see Table 5).

Competition Networks (inter-event) are utilized to analyze sport outcomes and results. In these studies, structural patterns and the relative performance of athletes or sport teams are denoted in outcomes or results of games and competitions or rankings. Therefore, the analysis of two-mode networks is often useful (e.g. athletes at the same competition). Eight studies (Bothner et al. 2012; Breznik \& Batagelj, 2012; Jessop, 2006; Leifer, 1990; Mukherjee, 2012; Radicchi, 2011; Saavedra et al., 2010; Sanders, 2011) fall into this category. Beyond the applications of SNA undertaken in the identified studies, a vibrant field for further applications of SNA could be the calculation of sports betting odds.

Interaction Networks (intra-event) are characterized by relations that are rule-based elements of the game (e.g. passes in soccer), which are analyzed for effectiveness. Different to Competition Networks, the relations are not encounters of teams and players or two-mode networks, but interactions of players within a team. Game-based Interaction Networks identified in this review are the networks of soccer teams (Duch et al., 2010; Grund, 2012), a basketball network (Fewell et al., 2012) and network of water polo players (Passos et al., 2011). Further studies in this field could analyze networks of on-field communication among team members, position exchange, or mutual support and cooperation such as in blocking moves (e.g. picks in basketball).

It has to be noted that the above two types of analyzing networks are specific for the field of sports comprising sport-specific nodes and ties. In contrast, the following four types can be relevant for research in other social contexts with the same types of nodes and ties. 
Table 5. Types of SNA in sports and physical activity research.

\begin{tabular}{|c|c|}
\hline Network type & Description \\
\hline Competition Networks $^{a}$ & $\begin{array}{l}\text { Results of games, rankings or structural patterns in sport (e.g. two- } \\
\text { mode networks such as athletes at same competitions, players in } \\
\text { same team). Relative performance or structural patterns are } \\
\text { analyzed. }\end{array}$ \\
\hline Interaction Networks (intra-event) ${ }^{a}$ & $\begin{array}{l}\text { Relations are rule-based elements of the game (e.g. passes), often ana- } \\
\text { lyzed for effectiveness. }\end{array}$ \\
\hline Inter-organizational Networks & $\begin{array}{l}\text { Network structures between organizations (e.g. collaboration between } \\
\text { sport providers, franchises, clubs, event organizers). }\end{array}$ \\
\hline Intra-organizational Networks & $\begin{array}{l}\text { Network structures within organizations (e.g. communication among } \\
\text { team members or within sport associations). }\end{array}$ \\
\hline Affiliation Networks & $\begin{array}{l}\text { Affiliations of social actors with aggregations of social actors (e.g. mem- } \\
\text { bership of individuals in organizations, participation of actors at } \\
\text { events). Data are usually collected as two-mode networks. }\end{array}$ \\
\hline Social Environments & $\begin{array}{l}\text { Representation of a sport-related social environment as a network in } \\
\text { which individual sports actors (e.g. athletes, individuals, teams) are } \\
\text { embedded. Analysis of support, influence etc. }\end{array}$ \\
\hline
\end{tabular}

Inter-organizational Networks describe structures between organizations. In our review, Inter-organizational Networks were identified in two domains: 'Sport management' (Cobbs, 2011; Cousens et al., 2012; Sallent et al., 2011; Seevers et al., 2010) and 'Sport-related scientific literature' (Agulló-Calatayud et al., 2008; Bruner et al., 2010; Love \& Andrew, 2012; Quatman \& Chelladurai, 2008a). While in the sport management studies relations among organization are analyzed, the studies on sport literature considered groups of authors and publications (i.e. social artifacts) and how they are related by citations. It has to be noted that the bibliometric use of SNA could also be categorized as a network type in its own right. However, we assigned them to Interorganizational Networks, considering groups of authors and single authors as social organizations. ${ }^{7}$ Apart from the types of organizations described here, there is a multitude of other related organizations of interest in the field of sports such as sports associations, franchises and clubs.

In contrast to networks of inter-organizational relations, Intra-organizational Networks describe network structures within organizations. Two studies of this type were found. In his seminal study, Zachary (1977) showed how the structural pattern of communication among social actors led to a social conflict of a karate club. Warner et al. (2012) studied social relations based on friendship, advice, trust and efficacy between members of sport teams and their impact on performance. Other interesting topics within this network type would be networks of information exchange (e.g. communication about tactics, dealing with injuries), exchange of resources (e.g. equipment, drugs), or coalition formation with regard to the election of presidents and board members in sport clubs or associations.

Affiliation networks are in between intra- and inter-organizational networks as they capture the membership of individuals in organizations, the participation of actors at events, or more generally the affiliation of social actors with aggregations of social actors. Such networks are usually collected as two-mode networks, but might be analyzed in terms of the one-mode projections obtained from them. For example, Kooij et al. (2009) studied co-appearances of Dutch soccer players (a one-mode network of 
players) obtained from their affiliation with teams (a two-mode network of players and matches). Onody and De Castro (2004) applied a similar technique. Examples for potential future studies include networks of board interlocks (e.g. in sport associations), corporate networks through sponsorship activities at events or of sport teams, and athletes' connections through common agents.

The last type of networks in sport is concerned with Social Environments. In these cases the sport-related Social Environment is represented as a network in which individual sport actors are embedded. The sport-related Social Environment influences the behaviour of these actors or is shaped by them. Two studies fall into this category. First, Hambrick (2012) showed that online social networking services such as Twitter influence the communication behaviour of sport event organizers and their followers. In the study conducted by Leung et al. (2011), it is analyzed how a mega sports event (the Olympic Games), representing the Social Environment, influences the behaviour of tourists with regard to visiting attractions (movement patterns). Further potential applications of SNA in this field would be the use of personal network analysis to understand the influence of the Social Environment on the quantity of sport participation, doping behaviour or the dealing of athletes with injuries.

Finally, we would like to highlight two more essential and closely associated aspects of network analyses in the field of sports: network interventions and network management. Since interventions and management are cross-sectional functions they do not fit into our typology of sport networks. However, they are important aspects of making purposeful use of network structures and closely related to the various types of sport networks we identified. Informed understanding and subsequent knowledge about the structures, mechanisms, and processes of the different types of sport networks form the basis for planned network interventions and management. In networks that emerged unnoticed or unintended by its members, interventions can be applied by targeting network structures. In this way, processes of dissemination in networks, for example in the context of community development, viral marketing or the targeted design and implementation of programmes, can be influenced. A specific example has been outlined by Walter, Wäsche, and Sander (2012). In their study of communication in workplace health management, they describe the importance of 'health brokers'. Brokers occupy key structural positions in firms and provide access to hard-to-reachemployees and communicate the benefits of physical activity. In planned networks, usually Inter-organizational Networks, as intended construct among the involved actors, practices and techniques of network management can be applied. These practices comprise the selection of network partners, the allocation of tasks, resources and responsibilities, the coordination of collaboration and the evaluation of inter-organizational relations (Sydow \& Windeler, 1997).

\section{Conclusion}

SNA is a new approach to the study of sport that is characterized by a relative dearth on empirical studies. However, the range of different topics indicates that this approach is promising in that it has a broad potential to improve our understanding of structures and processes unfolding in relations among social actors in sport. Interestingly, the majority of the identified studies in this paper are from academics with no sport- 
related affiliation. Nevertheless, three introductory papers to SNA and sport research and eight empirical studies (Bruner et al., 2010; Cousens et al., 2012; Hambrick, 2012; Love \& Andrew, 2012; Passos et al., 2011; Quatman \& Chelladurai, 2008a; Sallent et al., 2011; Warner et al., 2012) written by (or with) authors from sport-related research institutions show that the topic has gained momentum amongst sport scholars.

Considering the domains of the identified empirical work, most studies deal with the assessment of 'sport performance'. This domain, together with 'social structure of sport organization', represents a thematic aspect that is specific to sport. The dominance of this domain might partially be explained by the large amount of easy accessible, web-based data bases in professional and commercialized sport. Considering the applied methods of the reviewed studies, it has to be mentioned that, while some studies applied sophisticated methods of SNA, many studies lack methodological quality. Most of the studies are descriptive and based on rather simple measures of network centrality and cohesion. Only a few studies utilized explanatory methods to identify outcomes of networks in sport. Explicit conditions of network formation were not examined. A reason therefore might be that many procedures for testing hypotheses with network data were developed only recently and are not implemented in most standard statistical packages. For social network research in sport to progress, analytical procedures to test hypotheses based on permutation tests (Borgatti, Everett, \& Johnson, 2013) or on statistical modelling of cross-sectional observations of networks or on network dynamics (Snijders, 2011) should be considered.

The review provided the opportunity to develop a typology of SNA applications in sport research. Six different types were defined. While applications of SNA to investigate Social Environments, Affiliation Networks, and Inter- and Intra-organizational Networks are known in other fields of research, sport-specific Competition Networks and game-based Interaction Networks delineate a field of SNA that is peculiar to sport. In sum, this typology provides a systematic categorization of a new field of research and points to specific applications of SNA and fields of future research.

Although we presented a comprehensive review of SNA in sport research, it is by no means exhaustive and of limited scope. The number of searched databases was limited to three and only articles published before 2013 were included. Moreover, documents other than journal articles were not considered, leaving out monographs, book chapters, theses or conference abstracts. Lastly, the search terms and their combinations might have excluded some studies that bear relevance. We are aware of these limitations; however, we did not aim to provide an exhaustive and up-to-date review but to provide a comprehensive selection of studies that exemplifies various utilizations of SNA in sport research and serves the purpose of developing a conceptual typology.

To conclude, we offer some possible directions of research. An unprecedented amount of process-generated data is available to researchers. The amount of relational information within these data sets is considerable and provides various opportunities for research that should not be ignored. Potential future topics for analysis include, for example, the conditions and effects of Inter-organizational Networks on sport leagues, and sport associations or the effects of network-building and social capital (ties of friendship, trust, etc.) through organized sport activities in businesses, in school classes 
or competitive sporting teams. Additionally, other sport-specific actors such as managers, officials, agents, fans and sports-specific network ties such as membership in sport associations, joint use of sport facilities, joint participation in events, player transfer, or inter-individual relations between coaches and athletes are likely to lead to fresh perspectives. Moreover, other areas such as network analyses on physical activity in the context of public health as well as a focus on advanced methods of SNA, such as statistical modelling, and their utilization in sport research are worth further analysis. Conversely, we expect sport research to push a number of methodological developments in network science. In particular, research on interaction networks and the availability of comprehensive tracking data will increase the demand for methods for spatio-temporal networks. The typology of SNA applications in sports developed in this paper will serve to organize and guide future SNA research in the field of sport.

\section{Notes}

1. Despite the concern that there is a lack of a network theory, we note the substantial progress towards an integrated theoretical approach. See White (1992, 2008), Emirbayer (1997), Fuhse (2009), Wellman and Berkowitz (1988) for elaborations of network-theoretical approaches, and Borgatti and Halgin (2011) for research implications.

2. In this paper, the term 'soccer' is used for association football in order to avoid confusion with American football.

3. Jacob Moreno, in his seminal work 'Who shall survive?' (Moreno 1934, 213), presented a sociogram of a school's football team. The sociogram was based on mutual attraction. Moreno drew the conclusion that lack of cooperation and support may explain poor onfield performance. While we cannot be sure whether this was the first application of network thinking to the field of sports, Moreno's case shows that that sport was an applied field of network analysis from the very beginning.

4. However, a review showed the utility of SNA for health behaviour and physical activity research (MacDonald-Wallis, Jago, \& Sterne, 2012).

5. The starting point of the review was in 2013. Because our search yielded enough material to organize the potential scope of the use of SNA in sport research we did not extend our search to papers published later.

6. Gould and Gatrell's study of the Liverpool vs. Manchester United cup final of 1977 (Gould and Gatrell 1980) is another example of an early structural analysis in the field of sports, although not a network analysis in the strict sense.

7. While groups of authors clearly fall into the category of organizations, single authors of scientific papers do not. Hence, single authors would have to be considered as nodes in interpersonal networks. However, in most bibliometric networks groups of authors and single authors are connected (e.g. through citing each other), why we decided for reasons of simplicity to use just one term - Inter-organizational Networks - for these kind of networks.

\section{Disclosure statement}

No potential conflict of interest was reported by the authors.

\section{Notes on contributors}

Hagen Wäsche is a Senior Lecturer at the Department of Sports and Sport Sciences at the Karlsruhe Institute of Technology. His research interests lie in the fields of sport management, 
organization theory, sport sociology and the analysis of networks in sport. He is vice-chairman of the committee 'Sport and Space' of the German Society of Sport Science.

Geoff Dickson is an Associate Professor in the School of Sport and Recreation at Auckland University of Technology. His research interests include sport governance, and inter-organizational relationships. He is a former president of the Sport Management Association of Australia and New Zealand.

Alexander Woll is a Full Professor of Sport and Health at the Karlsruhe Institute of Technology (KT) and head of the Department of Sports and Sports Science. His main interests lie in the analysis of psycho-social determinants of physical activity and the examination of effects on motor, social, cognitive and health development over the life span. Further on he is interested in the optimization of methods and statistical analysis to capture sports activities, particularly in social networks. He is chairman of the committee 'Health' of the German Society of Sport Science and member of the expert group 'Physical Activity Promotion' of the German Federal Ministry of Health.

Ulrik Brandes is a Professor of Algorithmics at the University of Konstanz. His main interests lie in the analysis, visualization, and modelling of networks, and social networks in particular. He is an area editor for Network Science, associate editor for Social Networks, and a board member of the International Network of Social Network Analysis (INSNA).

\section{References}

Agulló-Calatayud, V., González-Alcaide, G., Valderrama-Zurián, J.C., \& Aleixandre-Benavent, R. (2008). Consumption of anabolic steroids in sport, physical activity and as a drug of abuse: An analysis of the scientific literature and areas of research. British Journal of Sports Medicine, 42, 103-109. http://dx.doi.org/10.1136/bjsm.2007.036228

Babbie, E.R. (1992). The practice of social research (6th ed.). Belmont, CA: Wadsworth Publishing.

Babiak, K. (2007). Determinants of interorganizational relationships: The case of a Canadian nonprofit sport organization. Journal of Sport Management, 21, 338-376. http://dx.doi.org/10.1123/ jsm.21.3.338

Borgatti, S.P., Everett, M.G., \& Johnson, J.C. (2013). Analyzing social networks. Los Angeles (CA): Sage.

Borgatti, S.P., \& Everett, M.G. (1999). Models of core/periphery structures. Social Networks, 21, 375-395. http://dx.doi.org/10.1016/S0378-8733(99)00019-2

Borgatti, S.P., \& Halgin, D.S. (2011). On network theory. Organization Science, 22, 1168-1181. http://dx.doi.org/10.1287/orsc.1100.0641

Borgatti, S.P., Mehra, A., Brass, D.J., \& Labianca, G. (2009). Network analysis in the social sciences. Science, 323, 892-895. http://dx.doi.org/10.1126/science.1165821

Bothner, M.S., Kim, Y.K., \& Smith, E.B. (2012). How does status affect performance? Status as an asset vs. status as a liability in the PGA and NASCAR. Organization Science, 23, 416-433. http:// dx.doi.org/10.1287/orsc.1110.0679

Brandes, U. \& Erlebach, T. (Eds). (2005). Network analysis: Methodological foundations. Berlin: Springer.

Brandes, U., Robins, G., McCranie, A., \& Wasserman, S. (2013). What is network science? Network Science, 1, 1-15. http://dx.doi.org/10.1017/nws.2013.2

Brass, D.J., Galaskiewicz, J., Greve, H.R., \& Tsai, W. (2004). Taking stock of networks and organizations: A multilevel perspective. Academy of Management Journal, 47, 795-817. http://dx.doi. org/10.2307/20159624

Breznik, K., \& Batagelj, V. (2012). Retired matches among male professional tennis players. J Sports Sci Med, 11, 270-278. 
Bruner, M.W., Erickson, K., Wilson, B., \& Côté, J. (2010). An appraisal of athlete development models through citation network analysis. Psychology of Sport and Exercise, 11, 133-139. http://doi. org/10.1016/j.psychsport.2009.05.008

Clauset, A., Shalizi, C.R., \& Newman, M.E.J. (2009). Power-law distributions in empirical data. SIAM Review, 51, 661-703. http://dx.doi.org/10.1137/070710111

Cobbs, J.B. (2011). The dynamics of relationship marketing in international sponsorship networks. Journal of Business \& Industrial Marketing, 26, 590-601. http://dx.doi.org/10.1108/ 08858621111179868

Cousens, L., Barnes, M., \& MacLean, J. (2012). Strategies to increase sport participation in Canada: The role of a coordinated network. International Journal of Sport Management and Marketing, 12, 198-216. http://dx.doi.org/10.1504/IJSMM.2012.052667

Cousens, L., \& Slack, T. (1996). Emerging patterns of inter-organizational relations: A network perspective of North American professional sport leagues. European Sport Management Quarterly, 3, 48-69.

Doreian, P., Batagelj, V., \& Ferligoj, A. (2004). Generalized blockmodeling of two-mode data. Social Networks, 26, 29-53. http://dx.doi.org/10.1016/j.socnet.2004.08.001

Diaz-Bone, R. (2006) Eine kurze Einführung in die sozialwissenschaftliche Netzwerkanalyse [A short introduction to social network analysis]. In Mitteilungen aus dem schwerpunktbereich methodenlehre vol. 57 [notes from the focus area methodology]. Berlin: Institut für Soziologie, Freie Universität Berlin.

Dickson, G., \& Cousens, L. (Eds.). (2008). Sport Organisations and Inter-Organisational Relationships (Special issue). International Journal of Sport Management and Marketing, 3(3).

Dickson, G., Arnold, T., \& Chalip, L. (2005). League expansion and interorganisational power. Sport Management Review, 8, 145-165. http://dx.doi.org/10.1016/S1441-3523(05)70037-1

Duch, J., Waitzman, J.S., \& Nunes Amaral, L.A. (2010). Quantifying the performance of individual players in a team activity. PLoS One, 5, e10937. http://dx.doi.org/10.1371/journal.pone.0010937

Fransen, K., Van Puyenbroeck, S., Loughead, T.M., Vanbeselaere, N., De Cuyper, B., Vande Brok, G., \& Boen, F. (2015). Who takes the lead? Social network analysis as a pioneering tool to investigate shared leadership within sports teams. Social Networks, 43, 28-38. http://dx.doi. org/10.1016/j.socnet.2015.04.003

Emirbayer, M. (1997). Manifesto for a relational sociology. American Journal of Sociology, 103, 281-317. http://dx.doi.org/10.1086/231209

Erickson, G.S., \& Kushner, R.J. (1999). Public event networks: An application of marketing theory to sporting events. European Journal of Marketing, 33, 348-365. http://dx.doi.org/10.1108/ 03090569910253189

Fewell, J.H., Armbruster, D., Ingraham, J., Petersen, A., \& Waters, J.S. (2012). Basketball teams as strategic networks. PLoS One, 7, e47445. https://doi.org/10.1371/journal.pone.0047445

Freeman, L.C. (1979). Centrality in social networks: Conceptual clarification. Social Networks, 1, 215-239. http://dx.doi.org/10.1016/0378-8733(78)90021-7

Freeman, L.C. (2004). The development of social network analysis: a study in the sociology of science. Vancouver, BC: Empirical Press.

Fuhse, J.A. (2009). The meaning structure of social networks. Sociological Theory, 27, 51-73. http://dx.doi.org/10.1111/j.1467-9558.2009.00338.x

Goldenberg, A., Zheng, A.X., Fienberg, S.E., \& Airoldi, E.M. (2009). A survey of statistical network models. Foundations and Trends in Machine Learning, 2, 129-233. http://dx.doi.org/10.1561/ 2200000005

Gould, P., \& Gatrell, A. (1980). The Liverpool-Manchester cup final: A structural analysis of a game. Social Networks, 2, 253-273. http://dx.doi.org/10.1016/0378-8733(79)90017-0

Granovetter, M. (1973). Strength of weak ties. American Journal of Sociology, 78, 1360-1380. http://dx.doi.org/10.1086/225469

Grund, T.U. (2012). Network structure and team performance: The case of English Premier League soccer teams. Social Networks, 34, 682-690. http://dx.doi.org/10.1016/j.socnet. 2012.08.004 
Grusky, O. (1963). The effects of formal structure on managerial recruitment: A study of baseball organization. Sociometry, 26, 345-353. http://dx.doi.org/10.2307/2786074

Hambrick, M.E. (2012). Six degrees of information: Using social network analysis to explore the spread of information within sport social networks. International Journal of Sport Communication, 5, 16-34. http://dx.doi.org/10.1123/ijsc.5.1.16

Hennig, M., Brandes, U., Pfeffer, J., \& Mergel, I. (2012). Studying social networks: a guide to empirical research. Frankfurt: Campus.

Holland, P., \& Leinhardt, S. (1976). Local structure in social networks. Sociological Methodology, 7, 1-45. http://dx.doi.org/10.2307/270703

Jessop, A. (2006). A measure of competitiveness in leagues: A network approach. Journal of the Operational Research Society, 57, 1425-1434. http://dx.doi.org/10.1057/palgrave.jors.2602122

Kadushin, C. (2012). Understanding social networks: Theories, concepts, and findings. New York, NY: Oxford University Press.

Knoke, D., \& Yang, S. (2008). Social network analysis (2nd ed.). Los Angeles, CA: Sage.

Kooij, R., Jamakovic, A., van Kesteren, F., de Koning, T., Theisler, I., \& Veldhoven, P. (2009). The Dutch soccer team as a social network. Connections, 29, 4-14.

Kossinets, G. (2013). Effects of missing data in social networks. Social Networks, 28, 247-268. http://dx.doi.org/10.1016/j.socnet.2005.07.002

Krackhardt, D. (1994). Graph theoretical dimensions of informal organizations. In K. Carley \& M. Prietula (Eds.), Computational organizational theory (pp. 89-111). Hillsdale, NJ: Lawrence Erlbaum Associaties.

Leifer, E.M. (1990). Enacting networks: The feasibility of fairness. Social Networks, 12, 1-25. http:// dx.doi.org/10.1016/0378-8733(90)90020-A

Leung, X.Y., Wang, F., Wu, B., Bai, B., Stahura, K.A., \& Xie, Z. (2011). A social network analysis of overseas tourist movement patterns in Beijing: The impact of the Olympic Games. International Journal of Tourism Research, 14, 469-484. http://dx.doi.org/10.1002/jtr.876

Love, A., \& Andrew, D.P.S. (2012). The intersection of sport management and sociology of sport research: A social network perspective. Sport Management Review, 15, 244-256. http://dx.doi. org/10.1016/j.smr.2011.08.001

Loy, J.W., Curtis, J.E., \& Sage, J.N. (1978). Relative centrality of playing position and leadership recruitment in team sports. Exercise \& Sport Sciences Reviews, 6, 257-284. http://dx.doi.org/10. 1249/00003677-197800060-00007

Loy, J.W., \& McElvogue, J.F. (1970). Racial segregation in American sport. International Review of Sport Sociology, 5, 5-24. http://dx.doi.org/10.1177/101269027000500101

Lusher, D., Koskinen, J., Robins, (Eds.). (2013). Exponential random graph models for social networks. In: Structural analysis in the social sciences. New York (NY): Cambridge University Press.

Lusher, D., Robins, G., \& Kremer, P. (2010). The application of social network analysis to team sports. Measurement in Physical Education \& Exercise Science, 14, 211-224. http://dx.doi.org/10. 1080/1091367X.2010.495559

MacDonald-Wallis, K., Jago, R., \& Sterne, J.A.C. (2012). Social network analysis of childhood and youth physical activity: A systematic review. American Journal of Preventive Medicine, 43, 636-642. http://dx.doi.org/10.1016/j.amepre.2012.08.021

Masuda, N., \& Konno, N. (2006). VIP-club phenomenon: Emergence of elites and masterminds in social networks. Social Networks, 28, 297-309. http://dx.doi.org/10.1016/j.socnet.2005.07.005

McPherson, M., Smith-Lovin, L., \& Cook, J.M. (2001). Birds of a feather: Homophily in social networks. Annual Review of Sociology, 27, 415-444. http://dx.doi.org/10.1146/annurev.soc.27.1.415

Milgram, S. (1967). The small world problem. Psychology Today, 1, 61-67.

Milo, R., Shen-Orr, S., Itzkovitz, S., Kashtan, N., Chklovskii, D., \& Alon, U. (2002). Network motifs: Simple building blocks of complex networks. Science, 298, 824-827. http://dx.doi.org/10.1126/ science.298.5594.824

Misener, L., \& Mason, D.S. (2006). Creating community networks: Can sporting events offer meaningful sources of social capital? Managing Leisure, 11, 39-56. http://dx.doi.org/10.1080/ 13606710500445676 
Moreno, J.L. (1934). Who shall survive? A new approach to the problem of human interrelations. Washington, DC: Nervous and Mental Disease Publishing.

Mukherjee, S. (2012). Identifying the greatest team and captain: A complex network approach to cricket matches. Physica A: Statistical Mechanics and Its Applications, 391, 6066-6076. http:// doi.org/10.1016/j.physa.2012.06.052

Newman, M.E.J. (2006). Modularity and community structure in networks. Proceedings of the National Academy of Sciences, 103, 8577-8582. http://dx.doi.org/10.1073/pnas.0601602103

Nixon, H.L. (1992). A social network analysis of influences on athletes to play with pain and injuries. Journal of Sport \& Social Issues, 16, 127-135. http://dx.doi.org/10.1177/ 019372359201600208

Nixon, H.L. (1993). Social network analysis of sport: Emphasizing social structure in sport sociology. Sociology of Sport Journal, 10, 315-321. http://dx.doi.org/10.1123/ssj.10.3.315

Norris, J., \& Jones, R.L. (1998). Towards a clearer definition and application of the centrality hypothesis in English Professional Association Football. Journal of Sport Behavior, 21, 181-195.

Onody, R.N., \& De Castro, P.A. (2004). Complex network study of Brazilian soccer players. Physical Review E-Statistical, Nonlinear, and Soft Matter Physics, 70, 037103. http://dx.doi.org/10.1103/ PhysRevE.70.037103

Passos, P., Davids, K., Araújo, D., Paz, N., Minguéns, J., \& Mendes, J. (2011). Networks as a novel tool for studying team ball sports as complex social systems. Journal of Science and Medicine in Sport, 14, 170-176. http://doi.org/10.1016/j.jsams.2010.10.459

Provan, K.G., Fish, A., \& Sydow, J. (2007). Interorganizational networks at the network nevel: A review of the empirical literature on whole networks. Journal of Management, 33, 479-516. http://dx.doi.org/10.1177/0149206307302554

Quatman, C., \& Chelladurai, P. (2008a). The social construction of knowledge in the field of sport management: A social network perspective. Journal of Sport Management, 22, 651-676. http://dx.doi.org/10.1123/jsm.22.6.651

Quatman, C., \& Chelladurai, P. (2008b). Social network theory and analysis: A complementary lens for inquiry. Journal of Sport Management, 22, 338-360. http://dx.doi.org/10.1123/jsm.22.3. 338

Raab, J., \& Kenis, P. (2009). Heading toward a society of networks: Empirical developments and theoretical challenges. Journal of Management Inquiry, 18, 198-210. https://doi.org/10.1177/ 1056492609337493

Radicchi, F. (2011). Who is the best player ever? A complex network analysis of the history of professional tennis. PLoS One, 6, e17249. https://doi.org/10.1371/journal.pone.0017249

Roderick, M. (1998). The sociology of risk, pain, and injury: A comment on the work of Howard L. Nixon II. Sociology of Sport Journal, 15, 64-79. http://dx.doi.org/10.1123/ssj.15.1.64

Saavedra, S., Powers, S., McCotter, T., Porter, M.A., \& Mucha, P.J. (2010). Mutually-antagonistic interactions in baseball networks. Physica A: Statistical Mechanics and Its Applications, 389, 1131-1141. http://dx.doi.org/10.1016/j.physa.2009.10.038

Sallent, O., Palau, R., \& Guia, J. (2011). Exploring the legacy of sport events on sport tourism networks. European Sport Management Quarterly, 11, 397-421. http://dx.doi.org/10.1080/ 16184742.2011.599208

Sanders, J. (2011). Ranking patterns in college football's BCS selection system: How conference ties, conference tiers, and the design of BCS payouts affect voter decisions. Social Networks, 33, 273-280. http://dx.doi.org/10.1016/j.socnet.2011.08.001

Schnettler, S. (2009). A structured overview of 50 years of small-world research. Social Networks, 31, 165-178. http://dx.doi.org/10.1016/j.socnet.2008.12.004

Scott, J. (2000). Social network analysis: $A$ handbook (2nd ed.). London: Sage.

Scott, J. (2012). Social network analysis: A handbook (3rd ed.). Los Angeles, CA: Sage.

Seevers, M.T., Skinner, S.J., \& Dahlstrom, R. (2010). Performance implications of a retail purchasing network: The role of social capital. Journal of Retailing, 86, 356-367. http://dx.doi.org/10. 1016/j.jretai.2010.07.002

Snijders, T. (2011). Statistical models for social networks. Annual Review of Sociology, 37, 129-151. http://dx.doi.org/10.1146/annurev.soc.012809.102709 
Steen, M., Hayasaka, S., Joyce, K., \& Laurienti, P. (2011). Assessing the consistency of community structure in complex networks. Physical Review E: Statistical, Nonlinear, and Soft Matter Physics, 84, 016111.http://dx.doi.org/10.1103/PhysRevE.84.016111

Sydow, J., \& Windeler, A. (1997). Komplexität und Reflexivität in Unternehmungsnetzwerken [Complexity and reflexivity in firm networks]. In W. Ahlemeyer \& R. Königswieser (Eds.), Komplexität managen: Strategie, konzepte und fallbeispiele [managing complexity: Strategy, concepts and case studies] (pp. 147-162). Wiesbaden: Gabler.

Walter, U.N., Wäsche, H., \& Sander, M. (2012). Dialogorientierte Kommunikation im Betrieblichen Gesundheitsmanagement [Dialogue-oriented communications in workplace health management]. Prävention Und Gesundheitsförderung, 7, 295-301. http://dx.doi.org/10.1007/s11553-0120357-y

Wäsche, H. (2015). Interorganizational cooperation in sport tourism: A social network analysis. Sport Management Review, 18, 542-554. http://doi.org/10.1016/j.smr.2015.01.003

Wäsche, H., \& Woll, A. (2010). Regional sports tourism networks: A conceptual framework. Journal of Sport \& Tourism, 15, 191-214. http://dx.doi.org/10.1080/14775085.2010.513146

Warner, S., Bowers, M.T., \& Dixon, M.A. (2012). Team dynamics: A social network perspective. Journal of Sport Management, 26, 53-66. http://dx.doi.org/10.1123/jsm.26.1.53

Wasserman, S., \& Faust, K. (1994). Social network analysis: Methods and applications. Cambridge: Cambridge University Press.

Watts, D.J. (1999). Networks, dynamics, and the small-world phenomenon. The American Journal of Sociology, 105, 493-527. http://dx.doi.org/10.1086/210318

Wellman, B., \& Berkowitz, S.D. (1988). Social structures: A network approach. Cambridge: Cambridge University Press.

White, H.C. (1992). Identity and control: A structural theory of social action. Princeton, NJ: Princeton University Press.

White, H.C. (2008). Identity and control: How social formations emerge (2nd ed.). Princeton, NJ: Princeton University Press.

Wolfe, R., Meenaghan, T., \& O'Sullivan, P. (2002). The sports network: Insights into the shifting balance of power. Journal of Business Research, 55, 611-622. http://dx.doi.org/10.1016/S01482963(00)00191-0

Zachary, W.W. (1977). An information flow model for conflict and fission in small groups. Journal of Anthropological Research, 33, 452-473. http://dx.doi.org/10.1086/jar.33.4.3629752

Zaheer, A., Gözübüyük, R., \& Milanov, H. (2010). It's the connections: The network perspective in interorganizational research. Academy of Management Perspectives, 24, 62-77.

Ziakas, V., \& Costa, C.A. (2010). Explicating inter-organizational linkages of a host community's events network. International Journal of Event and Festival Management, 1, 132-147. http://dx. doi.org/10.1108/17852951011056919 